\title{
Pierluigi Pellini, In una casa di vetro. Generi e temi del naturalismo europeo
}

\section{Mario Richter}

\section{(2) OpenEdition}

1 Journals

\section{Edizione digitale}

URL: https://journals.openedition.org/studifrancesi/26712

DOI: 10.4000/studifrancesi.26712

ISSN: 2421-5856

\section{Editore}

Rosenberg \& Sellier

\section{Edizione cartacea}

Data di pubblicazione: 1 avril 2007

Paginazione: 208

ISSN: 0039-2944

\section{Notizia bibliografica digitale}

Mario Richter, «Pierluigi Pellini, In una casa di vetro. Generi e temi del naturalismo europeo», Studi Francesi [Online], 151 (LI | I) | 2007, online dal 30 novembre 2015, consultato il 23 novembre 2021. URL: http:// journals.openedition.org/studifrancesi/26712 ; DOI: https://doi.org/10.4000/studifrancesi.26712

Questo documento è stato generato automaticamente il 23 novembre 2021.

\section{(c) $(1) \&$}

Studi Francesi è distribuita con Licenza Creative Commons Attribuzione - Non commerciale - Non opere derivate 4.0 Internazionale. 


\title{
Pierluigi Pellini, In una casa di vetro. Generi e temi del naturalismo europeo
}

\author{
Mario Richter
}

\section{NOTIZIA}

PIERLUIGI PELLINI, In una casa di vetro. Generi e temi del naturalismo europeo, Firenze, Le Monnier Università, 2004, pp. 264.

1 I saggi radunati in questo libro, quasi tutti già editi in diverse sedi, rivelano il carattere unitario di una esigenza critica alla quale potrebbe servire da introduzione generale l'utile libretto che l'A. pubblicò qualche anno fa col titolo Naturalismo e Verismo (Firenze, La Nuova Italia, 1998). L'interesse dell'opera consiste, in primo luogo, nella valutazione del Naturalismo in contesto europeo. Verga e Zola costituiscono il pressoché costante punto di riferimento dell'indagine e della riflessione critica. In secondo luogo, l'A. porta decisivi argomenti per rovesciare uno schema storiografico che vede nel Naturalismo un estremo sviluppo della tradizione romantica dell'Ottocento. In realtà, sulla base di una valutazione spesso rinnovata, il Naturalismo annuncerebbe piuttosto le avanguardie primonovecentesche, assumendo in tal modo il valore di una protoavanguardia. In questa prospettiva, la zoliana "casa di vetro", scelta come titolo generale del libro, assume la scontata poetica realista della trasparenza per orientarla in direzione opposta, ossia verso l'immaginario d'avanguardia (architettura in ferro e vetro, il plein air degli impressionisti e, aspetto piuttosto inatteso, la clinica psichiatrica concepita come "maison de verre" dall'alienista Ulysse Trélat). Pierluigi Pellini ci fa così compiere un interessante viaggio di riconoscimenti e talvolta di scoperte attraverso un significativo campionario di testi naturalisti, studiati con encomiabile accortezza critica e con sicura dottrina alla luce del rapporto fra temi e strutture narrative nonché fra temi e discorso sociale. 